\title{
Comparison of Novel Cleaning Solutions With Various Chelating Agents for Post-CMP Cleaning on Poly-Si Film
}

\author{
Tung Ming Pan, Tan Fu Lei, Fu Hsiang Ko, Tien Sheng Chao, Tzu Huan Chiu, Ying Hao Lee, and Chih Peng Lu
}

\begin{abstract}
In this study, various cleaning solutions containing chelating agents with carboxyl acid group ( $-\mathrm{COOH})$, such as ethylenediaminetetraacetic acid, citric acid and oxalic acid, were developed for post-poly-Si CMP cleaning. The chelating agent and tetramethylammonium hydroxide (TMAH) were simultaneously added into $2 \%$ ammonium hydroxide alkaline solution to promote the removal efficiency on particles and metallic impurities. The effectiveness of various cleaning recipes and their interaction mechanism with poly-Si surface were studied. We could explain the surface behavior of various cleaning solutions by the different molecular size and charge of chelating agents. Based on the mechanism, the behavior of surface particle and metallic impurity can be realized. The co-existence of TMAH with citric acid or oxalic acid in the alkaline cleaning solutions can significantly enhance the electrical property for the capacitor.
\end{abstract}

Index Terms-Chelating agents, citric acid, CMP, EDTA, oxalic acid, particles and metallic impurities, TMAH.

\section{INTRODUCTION}

A S THE geometry of devices continues to shrink and the complexity of circuits continues to grow, the miniaturization of modern integrated circuits demand a higher device yield and lower defect density in the active region of silicon devices [1]. For the reliability issue of nonvolatile memory devices, such as EPROM, EEPROM, and Flash memory, the requirement of polyoxide quality with higher breakdown electric field and lower leakage current would be necessary for longer data retention characteristics. Non-uniform thickness and surface roughness of the poly-Si would lead to defect formation on the poly-Si/polyoxide interface and thus deteriorating its electrical properties. Recently, chemical-mechanical polishing (CMP) process has become the mainstream planarization technique in miniaturization and integration of ULSI [2]. As the device dimension scales down, the significance to raise cleanliness of the wafer surface after polishing becomes more stringent than ever before. Brush scrubbing technology has been employed for many years and considered to be

Manuscript received July 3, 2000; revised May 18, 2001. This work was supported by Merck-Kanto Advanced Chemicals Ltd. through the Contract C88284 and National Science Council Taiwan, R.O.C., under Contract NSC89-2215E009-306.

T. M. Pan, T. F. Lei, and T. H. Chiu are with the Department of Electronics Engineering and Institute of Electronics, National Chiao Tung University, Hsinchu, Taiwan, R.O.C

F. H. Ko and T. S. Chao are with the National Nano Device Laboratories, Hsinchu, Taiwan, R.O.C.

Y. H. Lee and C. P. Lu are with Merck-Kanto Advanced Chemicals Ltd. Taoyuan, Taiwan, R.O.C.

Publisher Item Identifier S 0894-6507(01)09768-8. the most effective method on removing particles after the CMP process [3]. CMP is employed to reduce the surface roughness of deposited poly-Si film [4] and shows the improvement on polyoxide quality. However, the wafer surface after CMP process is seriously contaminated with particles and metallic impurities from polishing slurry. The particles will affect ULSI patterns. In addition, the fast diffusing metallic impurities such as copper, iron and chromium, even the least bit of contamination, will induce many crystal defects in Si wafer during thermal process [5].

The particle deposition on a hydrophilic wafer surface is a strong function of the $\mathrm{pH}$ value in the solution. Larger than $\mathrm{pH}$ 10 results in low particle deposition [6]. Numerous methods have been developed to improve the efficiency of removing particle. The most effective commercial method is the megasonic cleaning process [7]. The SC-1 solution in coupling with the megasonic cleaning process can remove organic and inorganic particles from surface at specific temperature ranging from $25{ }^{\circ} \mathrm{C}$ to $75{ }^{\circ} \mathrm{C}$ in the semiconductor industry. The particle cleaning process is very useful in cleaning after CMP process to remove the slurry on the poly-Si surface. In megasonic systems, the energy is produced by an array of piezoelectric crystals or transducers. These wafers carried with cassettes are immersing in the clean tank, such as SC-1 solution. The impact of high-frequency $(700-1000 \mathrm{kHz})$ sonic pressure waves on the wafers enhances the cleaning ability for the cleaning solutions. The force required to remove a particle from the wafer surface must be equal to (or exceed) the force of particle adhesion. In addition to particle removal, the megasonic process with SC-1 also demonstrates the capability to remove the copper contamination [7]. This observation is due to the readily exchange of copper ions with ammonia $\left(\mathrm{NH}_{4}^{+}\right)$, and the metallic impurities can be rinsed off.

A previous paper has reported the following problem for post-CMP cleaning on poly-Si film [8], both abrasive and metallic contaminant were left on the hydrophobic poly-Si surface and could not be removed with high efficiency in alkaline cleaning solutions. Up to now, the most effective way to remove particles from the polished poly-Si film can be achieved by using the diluted ammonium hydroxide solution. The particle removal mechanism is based on slightly etching the wafer surface, thus electrostatic repulsion is formed between the particle and wafer surface due to the negative potential. The tetramethylammonium hydroxide (TMAH) has been used to increase the particle removal efficiency [9]. However, metallic impurities tend to adhere on poly-Si surface after the cleaning with alkali solution. Our previous study has found that the 
TABLE I

VARIOUS ClEANING SOlutions USED FOR POST-CMP CLEANING

\begin{tabular}{c|c|c|c|c}
\hline solution & $\mathrm{NH}_{4} \mathrm{OH}$ & $\mathrm{NH}_{4} \mathrm{OH}:$ TMAH $(2.38 \%)$ & Chelating agent & $\mathrm{pH}$ \\
\hline $\mathrm{O}$ & $3 \%$ & 0 & 0 & 11.51 \\
\hline $\mathrm{A}$ & $2 \%$ & 0 & 0 & 11.40 \\
\hline $\mathrm{B}_{1}$ & $2 \%$ & $100: 1$ & EDTA $100 \mathrm{ppm}$ & 11.49 \\
\hline $\mathrm{B}_{2}$ & $2 \%$ & $100: 1$ & ETDA 200ppm & 11.48 \\
\hline $\mathrm{C}_{1}$ & $2 \%$ & $100: 1$ & Citric acid $100 \mathrm{ppm}$ & 11.51 \\
\hline $\mathrm{C}_{2}$ & $2 \%$ & $100: 1$ & Citric acid 200ppm & 11.50 \\
\hline $\mathrm{D}_{1}$ & $2 \%$ & $100: 1$ & Oxalic acid 100ppm & 11.50 \\
\hline $\mathrm{D}_{2}$ & $2 \%$ & $100: 1$ & Oxalic acid 200ppm & 11.50 \\
\hline
\end{tabular}

simultaneous spiking of TMAH and chelating agents in the cleaning solutions can effectively prevent the contamination problem of various metallic impurities on the poly-Si surface [9], [10]. The removal efficiency of particles and metallic impurities and the electrical characteristic after cleaning can be significantly improved by using this novel solution.

In silicon wafer cleaning, the metallic impurity is usually removed in the acid step (i.e., SC-2), while the particle and light organic are removed in the alkaline step (i.e., SC-1). Due to the difficulty of metallic impurity removal on the poly-Si surface after CMP process in the alkaline cleaning solution, a new cleaning method to overcome this problem remains to be developed. In this study, various chelating agents containing carboxyl acid group (-COOH) were investigated because chelating agent can react with metallic impurities to form stable metal-chelate complexes. This reaction prevents metal re-adhesion onto the poly-Si surface in alkaline cleaning solution. The removal efficiency of surface particle, organic contaminant and metallic impurity was carefully evaluated. The interaction mechanism of the chelating agent and the poly-Si surface was discussed. Furthermore, the particle, metallic impurities and electrical characteristics were also analyzed to evaluate the clean efficiency for the developed solutions.

\section{EXPERIMENTAL}

\section{A. Materials and Cleaning Solutions}

P-type $\langle 100\rangle$ wafers with 6-in diameter were used in this study (resistivity $15-25 \Omega \cdot \mathrm{cm}$ ). All reagents were of electronic or higher grade from Merck (Darmsadt, Germany). Table I lists recipes of various water-based cleaning solutions that are tested to find the best cleaning efficiency for poly-Si surface. The respective ethylenediaminetetraacetic acid (EDTA, $\mathrm{C}_{10} \mathrm{H}_{16} \mathrm{O}_{8} \mathrm{~N}_{2}$, $\mathrm{MW}=292)$, citric acid $\left(\mathrm{C}_{6} \mathrm{H}_{8} \mathrm{O}_{7}, \mathrm{MW}=192\right)$ and oxalic acid $\left(\mathrm{C}_{2} \mathrm{H}_{2} \mathrm{O}_{4}, \mathrm{MW}=90\right)$ are used in the cleaning solution. Another reagent, tetramethylammonium hydroxide (TMAH, MW =91), is also spiked into cleaning solutions of $\mathrm{B}_{1}, \mathrm{~B}_{2}, \mathrm{C}_{1}, \mathrm{C}_{2}, \mathrm{D}_{1}$, and $\mathrm{D}_{2}$. The EDTA has four $\mathrm{pKa}$ values of $1.99,2.67,6.16$, and 10.26. The citric acid has three pKa values of 3.14, 4.77, and 6.39, and the oxalic acid has only two pKa values of 1.23 and 4.19 [11].

\section{B. Capacitor Fabrication Process and the Cleaning Procedure}

The capacitor structure and manufacturing steps are shown in Fig. 1. A 5000- $\AA$ buffer oxide is thermally grown on the Si substrate. A 3000- $\AA$ poly-Si-I film was deposited on an oxide layer in low pressure chemical vapor deposition (LPCVD) system and then doped with $\mathrm{POCl}_{3}$ at $875{ }^{\circ} \mathrm{C}$ for $17 \mathrm{~min}$, which resulted in a resistivity of 40-80 $\Omega / \square$. The poly-Si-I CMP experiments were performed on a Westech-372M polisher with diluted CABOT SC-1 slurry. A 500 A poly-Si was removed during CMP process. After CMP process, the $2 \% \mathrm{NH}_{4} \mathrm{OH}$ solution was sprayed onto the wafer by $0.95 \mathrm{MHz}$ megasonic, followed by dispensing various cleaning solutions (in Table I) with PVA brush. After the cleaning operation, the RCA cleaning was performed. Then, a 120- $\AA$ interpolyoxide was deposited on the surface of the poly-Si-I films by tetra-ethyl-ortho-silicate (TEOS) in LPCVD system. These samples were rapidly annealed in an $\mathrm{N}_{2}$ ambient at $950{ }^{\circ} \mathrm{C}$ for $30 \mathrm{sec}$ within the rapid thermal reactor. Subsequently, a $3000 \AA$ poly-Si-II film was deposited and doped with a $40-80 \Omega / \square$ resistivity. After poly-Si-II was defined and etched by wet chemical solution, all samples were thermally grown to $1000 \AA$ thickness by wet oxidation. Contact holes were then opened, and a 5000- $\AA$ Al film was deposited and patterned to form capacitors. Finally, all samples were sintered for $30 \mathrm{~min}$ at $400{ }^{\circ} \mathrm{C}$ in an $\mathrm{N}_{2}$ ambient.

\section{Instrumental Analysis and Electrical Characterization}

To study the effectiveness of various wet wafer cleaning recipes, various surface analytical methods were used. The particle number with size higher than $0.2 \mu \mathrm{m}$ was counted by the Tencor surfscan Model 4500 system. The residual organic on the poly-Si surface was determined with Hitachi thermal desorption system (Model UG-21) and atmospheric pressure ionization mass spectrometer (Model UG-400P). The desorption temperature of the TDS-APIMS was ramped from room temperature to $600{ }^{\circ} \mathrm{C}$ at $10{ }^{\circ} \mathrm{C} / \mathrm{min}$. The surface out-gassing was analyzed at $\mathrm{m} / \mathrm{z} 30,44$, and 58 . The metallic impurity $(\mathrm{K}$, $\mathrm{Ti}, \mathrm{Cr}, \mathrm{Fe}, \mathrm{Cu}$, and $\mathrm{Zn}$ ) was determined using RIGAKU Model 3700 total reflection X-ray fluorescence spectrometer (TXRF). The surface roughness of the silicon wafer was measured by atomic force microscopy (AFM). The poly-oxide thickness was obtained by using Keithley $\mathrm{C}-\mathrm{V}$ system. The electrical properties of the poly-oxide of the J-E and time dependent dielectric breakdown (TDDB) characteristics were measured by using the Hewlett-Packard (HP) 4156B semiconductor parameter analyzer.

\section{RESULTS AND DISCUSSION}

\section{A. The Effect of Cleaning Solutions on Surface Roughness}

The importance of surface roughness on breakdown properties of thermal grown oxide layers has been previously demon- 


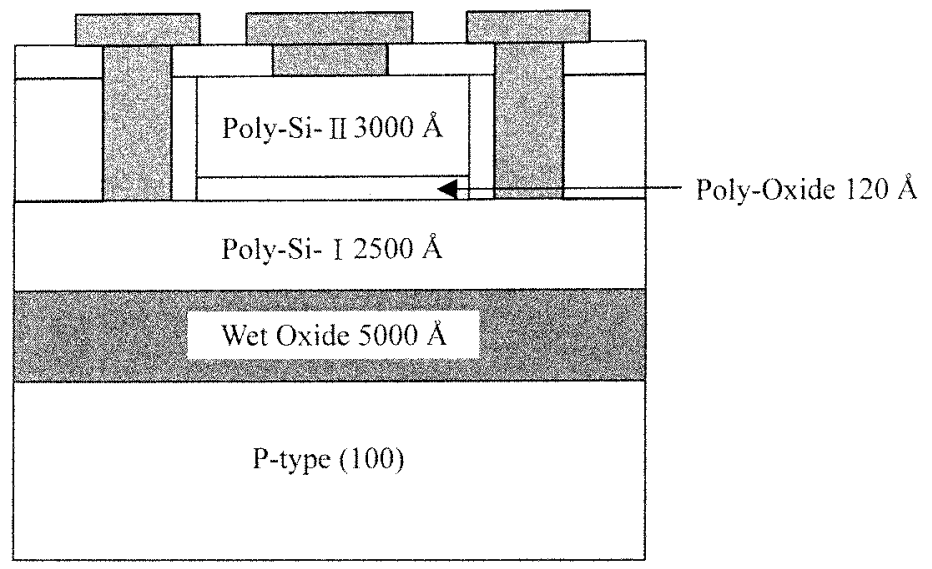

(a)

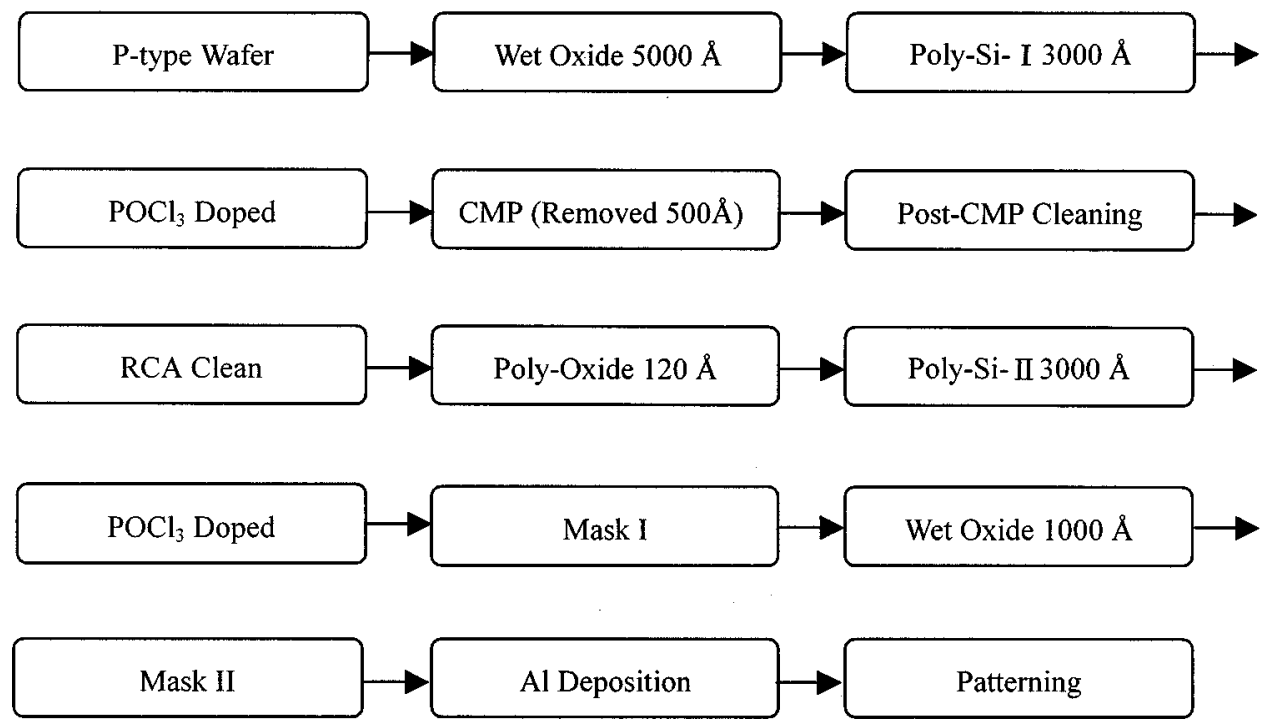

(b)

Fig. 1. The capacitor structure and processing steps of the poly-oxide capacitors using CMP process.

strated [12], [13]. Our previous report [10] also indicated the etching rate should show the positive relationship with the surface roughness of poly-Si film. Despite the suitable cleaning is beneficial for the device yield, the long time cleaning on silicon wafer has the detrimental effect due to surface roughness.

Fig. 2 illustrates the roughness of poly-Si film for various cleaning recipes. Except for cleaning with $3 \% \mathrm{NH}_{4} \mathrm{OH}$ (recipe $\mathrm{O})$, the surface roughness of other recipes is within 0.31 and $0.34 \mathrm{~nm}$. The resemblance of roughness for these recipes suggests the etching rate of the cleaning solution is still alike. Hence except for recipe $O$, the surface roughness is not the decisive reason for affecting the electrical performance. The most roughness of wafer surface after cleaning with recipe $\mathrm{O}$ will be predicted to exhibit the worse electrical behavior. This prediction will be discussed in latter section.

\section{B. The Physical and Chemical Properties of Poly-Si Surface After CMP and Cleaning}

The types of contamination after CMP can be classified into particle, organic and metal. In this study, after CMP process and subsequent cleaning with various solutions, the particle numbers on the poly-Si surface is determined. In addition, the wafer

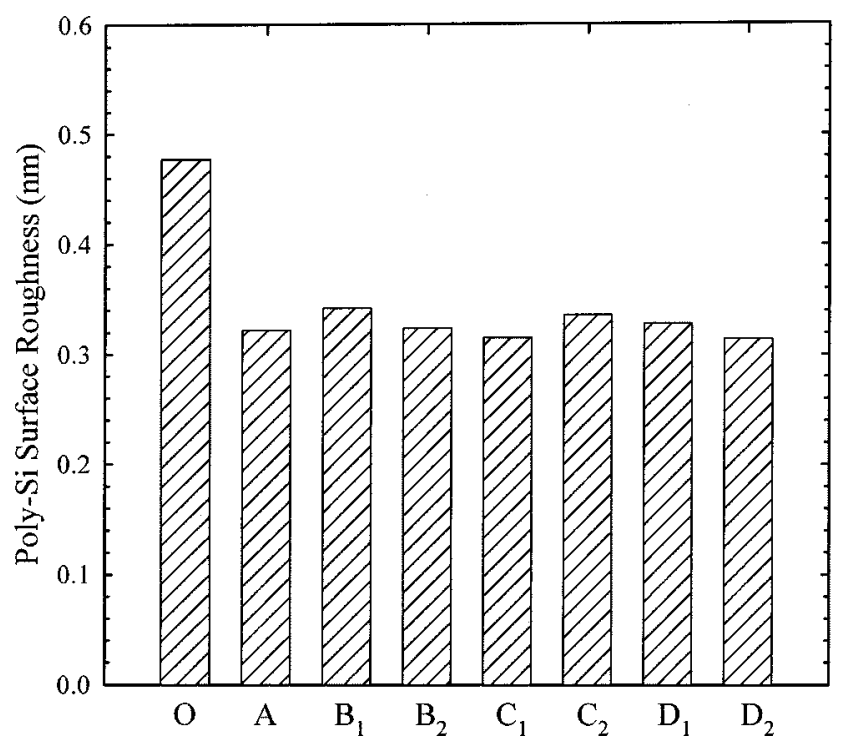

Fig. 2. The surface roughness of polished poly-Si after post-CMP cleaning in various solutions.

is analyzed with TDS-APIMS and TXRF to investigate the metallic and organic contamination. Fig. 3 shows the number of 


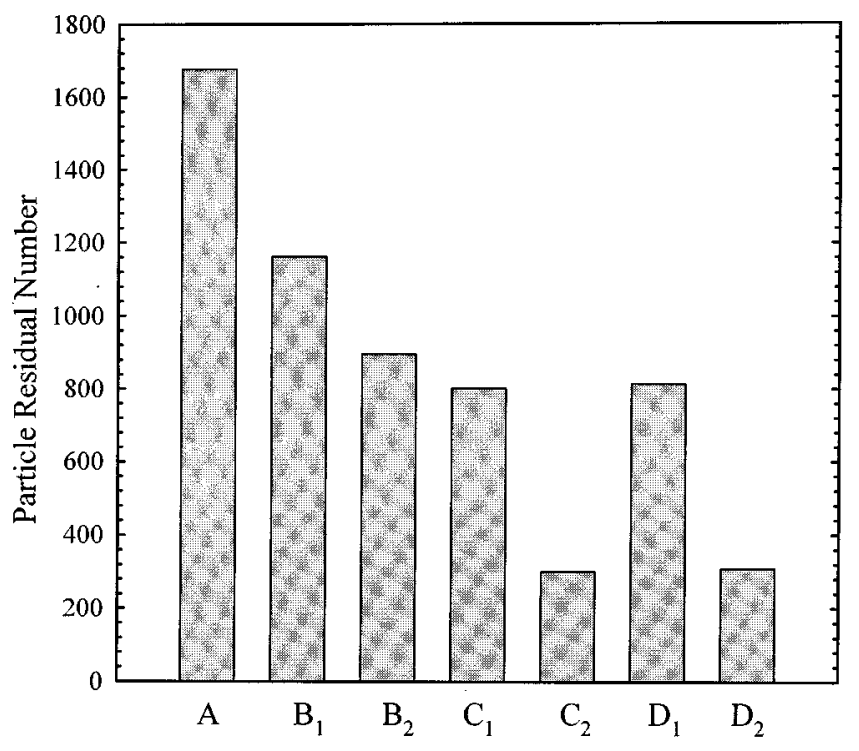

Fig. 3. Particle numbers on the polished poly-Si surface after post-CMP cleaning in different solutions.

particles on the wafer surface after post-poly-Si CMP cleaning for various solutions. It is found that these novel solutions (recipes $\mathrm{B}_{1}, \mathrm{~B}_{2}, \mathrm{C}_{1}, \mathrm{C}_{2}, \mathrm{D}_{1}$, and $\mathrm{D}_{2}$ ) exhibit higher particle removal efficiency than control recipe (only $2 \% \mathrm{NH}_{4} \mathrm{OH}$ solution). This observation is dependent on two reasons. Firstly, the TMAH can behave like a surfactant. The surfactant usually contains the organic main chain, and the hydrophilic and hydrophobic parts are in different sides of the main chain. Here, we assume the TMAH behaved like a surfactant due to its hydrophobic part (methyl group) and hydrophilic part (positively charge of nitrogen). These tetramethylammonium cations can adsorb on the hydrophobic $\mathrm{Si}-\mathrm{H}$ surface via van der Waals force. According to the prediction of our previous report [10], the surface state becomes hydrophilic after post-poly-Si CMP cleaning with TMAH-containing solution. This change of surface state can prevent the direct approach of particle, and facilitate the particle removal by the cleaning solution. The second one to affect the particle removal is the co-existing chelating agent. Here, we propose the effects of charge and size (or molecular weight) to explain the mechanism of particle removal. This model is based on Stern model [14]. Fig. 4 depicts the interaction of hydrophilic particle with the surface tetramethylammonium cations at alkaline condition $(\mathrm{pH}>$ 11.4). Chelating agents, such as EDTA, citric acid, and oxalic acid, appear in anion forms at solution $\mathrm{pH}$ higher than their $\mathrm{pKa}$ values. The penetration ability of the chelating agent into the interfacial region of particle and tetramethylammonium layer can absolutely influence the particle removal. Fig. 4 demonstrates the formation of surface double layer by the proposed cleaning solution.

As in such basic condition $(\mathrm{pH}>11.4)$, the acidhydrogen can be fully desorbed. The net negative charges are 4, 3, and 2 for EDTA, citric acid and oxalic acid, respectively. On considering the penetration of chelating agent illustrated in Fig. 4, the higher charge for chelating agent facilitates the interaction with the tetramethylammoniumcations. On the contrary, the large size(molecularweight) of chelating agent will face penetrating hindrance. If we consider the ratio of charge to molecular weight (size), citric acid and oxalic acid have higher ratio than EDTA. This observation suggests the $\mathrm{C}_{1}, \mathrm{C}_{2}, \mathrm{D}_{1}$, and $\mathrm{D}_{2}$ recipes have better performance on particle removal than EDTA-containing recipes.

The intensity of surface organic is determined with TDSAPIMS measurement. The peak intensities (obtained at 30, 44, and $58 \mathrm{~m} / \mathrm{z}$ ) for cleaning solutions (recipes $\mathrm{B}_{1}, \mathrm{~B}_{2}, \mathrm{C}_{1}, \mathrm{C}_{2}, \mathrm{D}_{1}$, and $\mathrm{D}_{2}$ ) are about in the range 1-2 fold than solution $\mathrm{A}$. After succeeding RCA cleaning, the organic residuals on the wafers show the same intensity from TDS-APIMS measurement. The latter electrical result demonstrates the level of residual organic has no degrading effect. Another important indicator to check the cleaning efficiency is the metallic contamination. The 1999 ITRS (International Technology Roadmap for Semiconductors) indicates the control limit of surface metal is about $10^{4}$-fold more critical than that of the organic component. The metal contamination is also a decisive factor on influencing the device yield. Verhaverbeke et al. [15] have reported that metal contamination can degrade the oxide breakdown properties by generating silicon surface roughness or by the formation of defect spots during oxidation. As if the concentration of residual metallic contamination on the silicon surface becomes higher, the oxide reliability (charge-to-breakdown) gradually decreases.

Fig. 5 shows the metal concentrations measured with TXRF instrument. It is very clear that the metallic contaminants are significantly removed by using the novel solutions, especially for the removal of $\mathrm{K}, \mathrm{Ti}, \mathrm{Cr}$, and $\mathrm{Fe}$ ions. The chelating agent reacts with metal ion as in the forms of metal-chelate complex. This reaction prevents the precipitate on the poly-Si surface in a form of metal hydroxide during high $\mathrm{pH}$ solution. It clearly demonstrates that cleaning solution $\mathrm{B}_{1}$ is not suitable to remove the metals of $\mathrm{K}$ and $\mathrm{Ti}$. This finding can be also explained from the mechanism appearing in Fig. 4 that the bulky EDTA can hardly react with the trap metal ion on poly-Si surface due to the lower ratio of charge to size. Solution $\mathrm{C}_{2}$ shows the better removal efficiency on metal than $\mathrm{C}_{1}$, indicating the concentration effect of chelating agent. Fig. 5 demonstrates the higher amount of chelating agent is beneficial for metal removal. However, the cost and the chelating agent contamination need further evaluation.

On considering roughness, particle, organic and metal effects, the cleaning solutions with additives of citric acid and oxalic acid have significant efficiency on particle and metal removal. The next section will demonstrate their electrical behaviors.

\section{Electrical Property for Various Cleaning Solutions}

Fig. 6 shows Weibull distributions of electric breakdown field, it is demonstrated that polished poly-Si-I films with using solution $\mathrm{A}$ (only $2 \% \mathrm{NH}_{4} \mathrm{OH}$ ) show a lower electric breakdown distribution than other solutions. However, using cleaning solution $\mathrm{C}_{2}$ on polished poly-Si-I film shows the highest electric breakdown distribution for these chelating agents. This observation is attributed to the enhancement of cleaning efficiency by combining the TMAH and citric acid on the removal for particle and metallic impurity debris. The removal efficiency of metallic impurity and particle residual on the poly-Si surface has some relative with the concentration of chelating agents. 

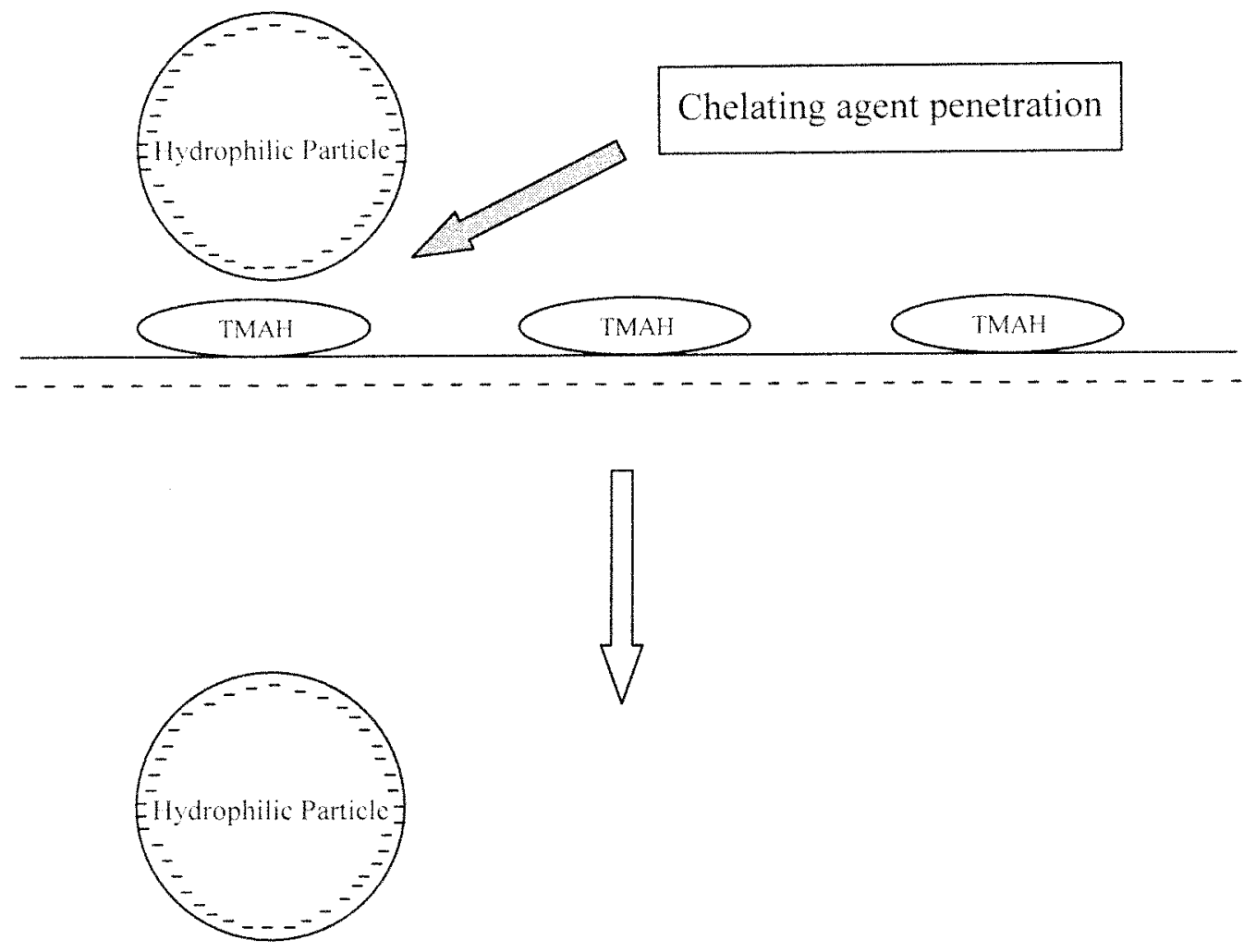

\section{Chelating agent anions}

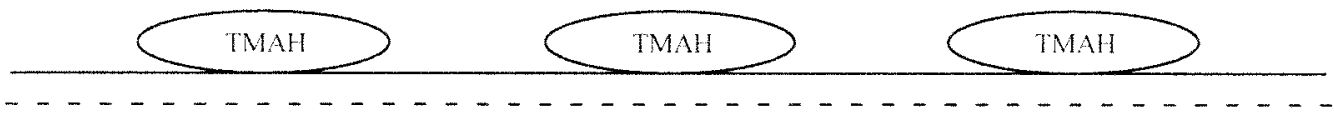

Fig. 4. The interaction mechanism of hydrophilic particle in the TMAH and chelating agent containing solutions.

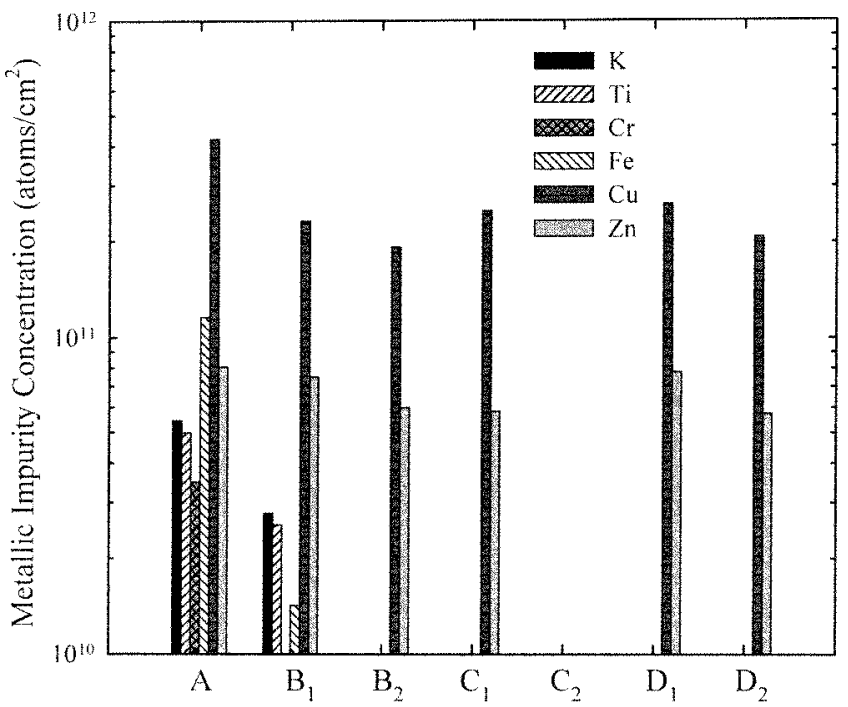

Fig. 5. The metal concentration on poly-Si surface after post-CMP cleaning for different solutions.

To investigate the poly-oxide reliability, charge-to-breakdown $\left(Q_{b d}\right)$ measurements were performed on capacitors. In Fig. 7, the Weibull distributions are shown under positive constant current density at $+20 \mathrm{~mA} / \mathrm{cm}^{2}$ stress. The distribution

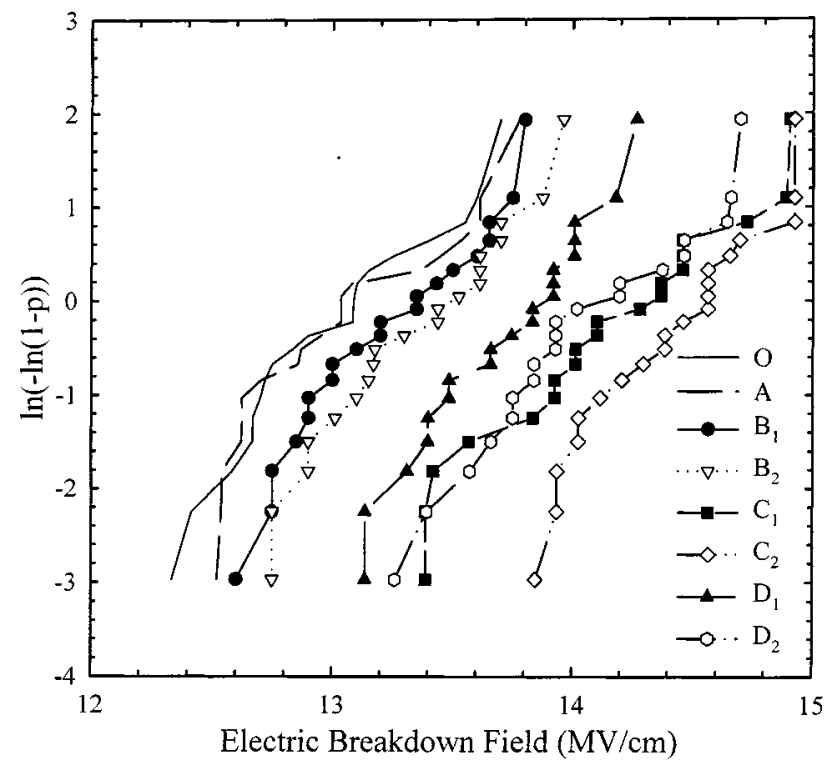

Fig. 6. The breakdown field distribution of capacitors after the CMP-processes with using different cleaning solutions for top gate applied positive bias.

for capacitor using cleaning solution $\mathrm{C}_{2}$ for poly-Si film after CMP process shows a slightly higher $Q_{b d}$. This result is 


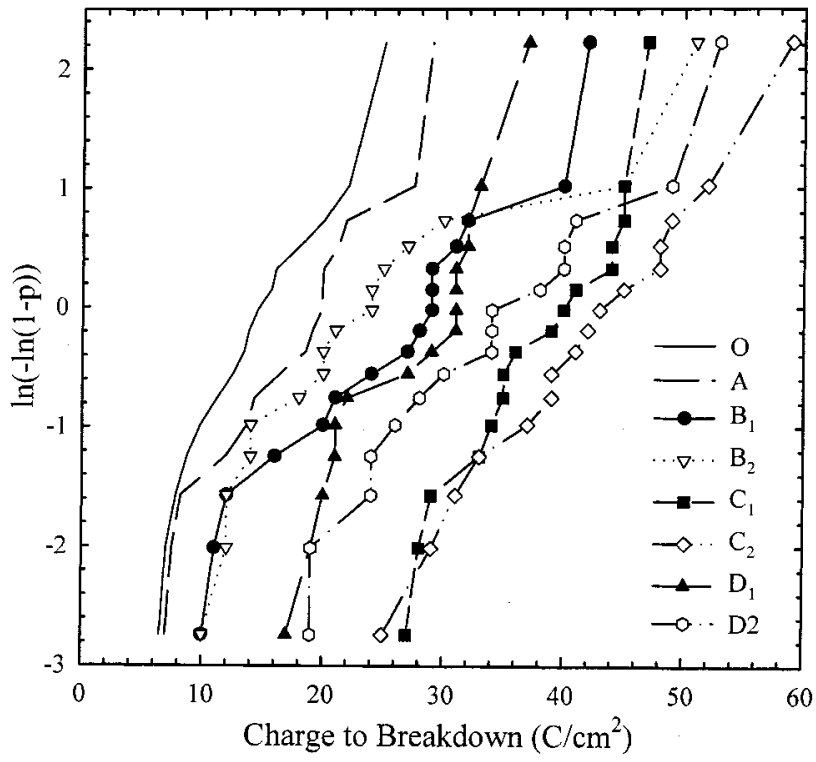

Fig. 7. The charge-to-breakdown $\left(Q_{b d}\right)$ of capacitors under positive constant current density stress.

consistent with the removal efficiency of particle and metallic impurity mentioned in the early. Therefore, citric acid and TMAH are suggested to add into alkaline cleaning solution for improving the removal of particle and metallic impurity. This finding can minimize the contamination and ensure the reliability of poly-Si-I film after CMP process.

\section{CONCLUSION}

In the paper, various cleaning solutions containing chelating agents with carboxyl acid group (-COOH) were explored for their influences on the surface roughness of poly-Si-I. We found the removal efficiency of particle and metallic impurity and the electrical characteristic can be significantly improved for postpoly-Si CMP cleaning by using these novel solutions. By adding the TMAH and chelating agent (citric acid with $200 \mathrm{ppm}$ ) into $2 \%$ ammonium hydroxide $\left(\mathrm{NH}_{4} \mathrm{OH}\right)$ alkaline aqueous solution, the residual metallic impurities and particles on the wafer surface and the electrical characteristics of poly-oxide capacitors are significantly improved for post-CMP cleaning.

\section{ACKNOWLEDGMENT}

The authors would like to thank the staff of National Nano Device Laboratory for their technical help.

\section{REFERENCES}

[1] S. M. Sze, VLSI Technology, 2nd ed. New York: McGraw-Hill, 1988, ch. 14.

[2] G. Bai, C. Chiang, J. N. Cox, S. Fang, and D. S. Gardner, "Copper interconnection deposition techniques and integration," in Symp. VLSI Tech. Dig., 1996, pp. 48-49.

[3] D. Hymes, I. Malik, J. Zhang, and R. Emami, "Brush scrubbing emerges as future wafer-cleaning technology," Solid State Technol., pp. 209-214, July 1997.
[4] T. F. Lei, J. Y. Cheng, S. Y. Shiau, T. S. Chao, and C. S. Lai, "Characterization of polysilicon oxides thermally grown and deposited on the polished polysilicon films," IEEE Trans. Electron Devices, vol. 45, pp. 912-917, 1998 .

[5] N. Miyashita, M. Shimomura, Y. Minami, I. Katakabe, H. Nojo, H. Ohashi, and M. Abe, "A new post CMP cleaning method for trench isolation process," in ISMIC'96, 1996, pp. 161-168.

[6] M. Itano, F. W. Kern, Jr., R. W. Rosenberg, M. Miyashita, I. Kawanabe, and T. Ohmi, "Particle deposition and removal in wet cleaning processes for ULSI manufacturing," IEEE Trans. Semiconduct. Manufact., vol. 5, pp. 114-120, 1992

[7] S. Shwartzman, A. Mayer, and W. Kern, "Megasonic particle removal from solid-state wafers," RCA Rev., vol. 46, pp. 81-105, 1985.

[8] G. J. Pietsch, G. S. Higashi, and Y. H. Chabal, "Chemomechanical polishing of silicon: Surface termination and mechanism of removal," Appl. Phys. Lett., vol. 64, pp. 3115-3117, 1994.

[9] T. M. Pan, T. F. Lei, C. C. Chen, T. S. Chao, M. C. Liaw, W. L. Yang, M. S. Tsai, C. P. Lu, and W. H. Chang, "Novel cleaning solutions for polysilicon film post chemical mechanical polishing," IEEE Trans. Electron Device Lett., vol. 21, pp. 338-340, 2000.

[10] T. M. Pan, T. F. Lei, F. H. Ko, T. S. Chao, M. C. Liaw, and C. P. Lu, "One-step cleaning solution to replace the conventional RCA two-step cleaning recipe for pre-gate oxide cleaning," J. Electrochem. Soc., vol. 148, June 2001.

[11] J. Bjerrum, G. Schwarzenbach, and L. G. Sillen, Stability Constants. London, U.K.: The Chemical Society, Burlington House, 1957, p. 76.

[12] T. Ohmi, M. Miyashita, M. Itano, T. Imaoka, and I. Kawanabe, "Dependence of thin-oxide films quality on surface microroughness," IEEE Trans. Electron Devices, vol. 39, pp. 537-545, 1992.

[13] M. Heyns, C. Hasenack, R. De Keersmaecker, and R. Falster, "Impact of silicon surface characteristic on MOS device yield for ULSI," Microelectr. Eng., vol. 10, pp. 235-257, 1993.

[14] P. H. Rieger, Electrochemistry. Englewood Cliffs, NJ: Prentice-Hall, 1987, p. 71.

[15] S. Verhaverbeke, M. Meuris, P. W. Mertens, M. M. Heyns, A. Philipossian, D. Graf, and A. Schnegg, "The effect of metallic impurities on the dielectric breakdown of oxides and some new ways of avoiding them," in IEDM Tech. Dig., 1991, pp. 71-74.

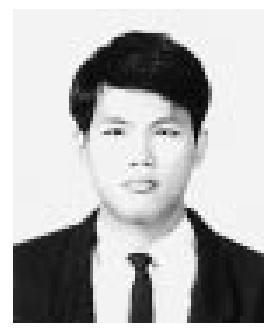

Tung Ming Pan was born in Taipei, Taiwan, R.O.C., in 1970. He received the B.S. degree from the Department of Electronics Engineering, National Chiao-Tung University (NCTU), Hsinchu, Taiwan, R.O.C., in 1997 and the Ph.D. degree from the Institute of Electronics, NCTU, in 2001.

He is currently a Principal Engineer in the LOGIC Development Department, Technology and Process Development Division (TD), UMC. His current research areas focus on the development novel cleaning solutions for pre-gate oxide cleaning and poly-Si film post-CMP. Applications of his research include the ultrathin oxynitride films and high-k gate dielectric materials for ultralarge scale integrated devices.
Tan Fu Lei was born in Keelung, Taiwan, R.O.C., on September 17, 1944. He received the B.S. degree in electrical engineering from National Cheng Kung University, Tainan, Taiwan, R.O.C., in 1967 and the M.S. and Ph.D. degrees in electronics engineering from National Chiao Tung University, Hsinchu, Taiwan, R.O.C., in 1970 and 1979, respectively.

From 1970 to 1972, he was with the Fine Products Microelectronics Corporation, Taiwan, R.O.C., as an Engineer working on the fabrication of small-signal transistors. From 1980 to 1982, he was the Plant Manager of Photronic Corporation, Taiwan, R.O.C. In 1983, he joined the faculty at National Chiao Tung University as an Associate Professor in the Department of Electronics Engineering and the Institute of Electronics. During 1984 to 1986, he was the Director of the Semiconductor Research Center. During 1991 to 1998, he also was the deputy director of the National Nano Device Laboratory. Presently he is a Professor of the Department of Electronics Engineering and the Institute of Electronics. His research interests are semiconductor devices and VLSI technologies. 


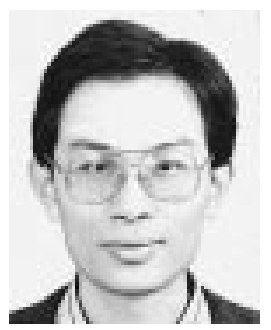

Fu Hsiang Ko was born in Hsinchu, Taiwan, R.O.C., in 1965. He received the B.S. and M.S. degrees in chemistry from National Tsing Hua University and National Taiwan Normal University in 1989 and 1991, respectively, and the Ph.D. degree in nuclear science from National Tsing Hua University in 1996.

He joined the NDL as an Associate Researcher in October 1996. He is currently engaged in developing the radioactive tracer and analytical methods on lithographic and cleaning processes.

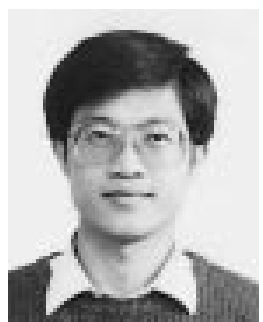

Tien Sheng Chao was born in Penghu, Taiwan, R.O.C., in 1963. He received the Ph.D. degree in electronics engineering from National Chiao-Tung University, Hsinchu, Taiwan, R.O.C., in 1992.

He jointed the National Nano Device Laboratories (NDL) as a Associate Researcher in July 1992, and became as a Researcher in 1996. He was engaged in developing the thin dielectrics preparations and cleaning processes. He is presently responsible for the deep submicron device integration at NDL.
Tzu Huan Chiu was born in Taichung, Taiwan, R.O.C., in 1976. He received the B.S. degree from the Department of Electronics Engineering, National Chiao-Tung University (NCTU), Hsinchu, Taiwan, R.O.C., in 1998 and the M.S. degree from the Institute of Electronics, NCTU, in 2000

His research interests focus on the development of novel cleaning solutions for ultralarge scale integrated applications.

Ying Hao Lee was born in Yunlin, Taiwan, R.O.C., in 1967. He received the B.S degree in chemistry from Chung-Yuan Christian University, Chung-Li, Taiwan, R.O.C., in 1991 and the Ph.D. degree in analytical chemistry from National Taiwan University, Taipei, Taiwan, R.O.C. in 1995.

$\mathrm{He}$ is currently the Manager of the Product Development Department with Merck-Kanto Advanced Chemicals Ltd., Taoyuan, Taiwan, R.O.C. His current research interests include instrumental, material, and ultraface analysis. His areas of expertise includes wafer-Fab processes, developing new process chemicals with proprietary chemistry.

Chih Peng Lu was born in Tainan, Taiwan, R.O.C., in 1959. He received the B.S. degree in chemistry from National Tsing Hua University, Taiwan, R.O.C. in 1981 and the M.B.A. degree from Saginaw Valley State University, University Center, MI, in 1998.

He is currently the Managing Director of Merck-Kanto Advanced Chemicals Ltd., Taoyuan, Taiwan, R.O.C. 